\title{
Detecting molecular changes in Vimy flaxseed protein structure using synchrotron FTIRM and DRIFT spectroscopic techniques: Structural and biochemical characterization
}

\author{
K.J. Doiron, P. Yu*, C.R. Christensen, D.A. Christensen and J.J. McKinnon \\ College of Agriculture and Bioresources, University of Saskatchewan, Saskatoon, SK, Canada
}

\begin{abstract}
Mid-IR techniques were used to characterize any changes that occurred on a molecular level in flaxseed that had been heated using an autoclave. The objectives were to investigate the effects of autoclave heating on differences in diffuse reflectance infrared Fourier transform (DRIFT) and synchrotron-based Fourier transform infrared microspectroscopy (SFTIRM) based measurements of the protein $\alpha$-helix to $\beta$-sheet ratio for flaxseed (Linum usitatissimum), cv. Vimy. Hierarchical cluster analysis (CLA) and principal components analysis (PCA) were also conducted to identify molecular differences in the DRIFT spectra. Flaxseed samples were kept raw for the control or autoclaved in batches at $120^{\circ} \mathrm{C}$ for 20,40 or 60 min for treatments 1,2 and 3, respectively. DRIFT analysis of protein secondary structure ratios showed a decrease $(P<0.05)$ in the $\alpha$-helix to $\beta$-sheet ratio for the whole seed while the results from synchrotron SFTIRM spot data from the endosperm tissue in flaxseed showed autoclaving had the opposite effect $(P>0.05)$. CLA and PCA were successfully used to make distinctions between the different treatment spectra and showed enhanced sensitivity upon selection of a smaller spectral window to include only the amide I and II portion of the IR spectrum. Our results indicated that autoclaving had a great enough effect on the mid-IR spectrum of flaxseed to identify the altered $\alpha$-helix to $\beta$-sheet ratio and subsequently differentiated between the treatments using PCA and CLA suggesting greater sensitivity of mid-IR spectral methods in identifying the effect of heat treatment on protein secondary structure. Future study is needed to quantify the relationship between protein secondary structure and protein functionality.
\end{abstract}

Keywords: Molecular structure, flaxseed protein, synchrotron IR, spectroscopic techniques

\section{Abbreviations}

ADIP: Acid detergent insoluble protein

CLA: Hierarchical cluster analysis

CNCPS: Cornell Net Carbohydrate and Protein System

CP: Crude protein

IR: Infrared

NDIP: Neutral detergent insoluble protein

\footnotetext{
${ }^{*}$ Corresponding author: Peiqiang Yu, College of Agriculture and Bioresources, University of Saskatchewan, Room 6D10, 51 Campus Drive, Saskatoon, SK, Canada, S7N 5A8. Tel.: +1 306966 4150; E-mail: peiqiang.yu@usask.ca.
} 
DRIFT: Diffuse reflectance infrared Fourier transform

NPN: $\quad$ Non-protein nitrogen

PCA: Principal components analysis

SCP: $\quad$ Soluble crude protein

SFTIRM: $\quad$ Synchrotron radiation-based Fourier Transform Mid-IR Microspectroscopy

\section{Introduction}

Current methods of food/feed evaluation, particularly for protein quality, are typically slow and cumbersome processes that require the destruction of a sample for any given measurement during "wet" chemical analysis. The information gleaned from such procedures is also not totally in context; that is to say some pertinent information is lost due to the process by which the measurements are taken. Part of the reason for this is that these standard methods destroy any spatial information as well as the distribution of those elements of interest [3]. These elements may be linked to degradability and digestibility in human/animals.

Vibrational spectroscopy or mid-Infrared spectroscopy has the capacity to overcome some of the issues with modern food/feed characterization methods. The results from mid-IR spectroscopy are complex in nature. The information contained within each spectra is not only related to the chemical bonds in each sample but interrelations between these chemical bonds [10]. So rather than look at the components of interest separate from one another, we can look at plant molecular structure in vivo.

When a synchrotron (which is million times brighter than sunlight) is used as the source of infrared light it is known as Synchrotron-based FTIR Microspectroscopy (SFTIRM). This coupling permits an even greater amount of information to be gathered from a sample of interest at both the cellular and molecular levels. The qualities of synchrotron light, including brightness and source size, permit IR spectroscopic measurements to be made on a sub-cellular scale thus allowing us to link quantity, interrelationships, and localization of compounds of interest all in a single experiment [16]. This mid-IR technique permits a greater understanding of food/feed structures at the cellular level [17], and with further work, will allow a more complete characterization of those food/feed traits related to quality.

One feature of protein that can be quantified with mid-IR methods is its secondary structure which is linked to protein digestibility and degradability [21]. This linkage is due to digestion being a complex process where any kind of steric issues at the molecular level, such as those presented by the different secondary structures, will ultimately affect the access enzymes will have to the food/feed constituents. Heating has also been demonstrated to alter the relative amounts of each secondary structure, thus having possible connections to alterations in degradability [18].

The objective of this study was to use both DRIFT and SFTIRM techniques with multivariate molecular spectral analysis as a mean of detecting heat induced changes to food/feed protein. Using multivariate molecular spectral analysis techniques as well as measuring $\alpha$-helix and $\beta$-sheet ratios should allow us to identify molecular differences between different autoclaved flaxseed treatments. The goal was to attempt to understand and identify spectroscopic signatures that are associated with changes in food/feed degradability. The hypothesis of this study was that autoclaving would induce spectroscopic changes to the flaxseed spectra that we can characterize with DRIFT and SFTIRM and may have a link to differences in degradability and digestibility in animals/humans. 


\section{Materials and methods}

\subsection{Flaxseed heating and processing}

Flaxseed (Linum usitatissimum) (cv. Vimy) grown near Moose Jaw, Saskatchewan during the 2005 growing year was provided by Shamrock Seeds Ltd. (Saskatoon, Saskatchewan). Flaxseed was heated by autoclave (Amsco Eagle SG-3031, STERIS Corporation) in autoclave trays at a temperature of $100^{\circ} \mathrm{C}$ for 20, 40 and 60 min as treatment 1, 2 and 3, respectively. Control treatments were kept raw.

\subsection{Chemical analysis}

All samples for chemical analysis were ground through a $1 \mathrm{~mm}$ screen. Crude protein (CP, AOAC official method 984.13) content was analyzed according to the procedure of the AOAC [1]. The acid (ADIN) and neutral detergent insoluble N (NDIN) values were determined according to the procedures of Licitra et al. [6]. The non-protein N (NPN) content was analyzed by precipitating true protein with tungstic acid and calculated as the difference between total $\mathrm{N}$ and the $\mathrm{N}$ content of the residue after filtration [6]. Total soluble crude protein (SCP) was determined by incubating the sample with bicarbonate-phosphate buffer and filtering through Whatman \#54 filter paper [12]. The detailed chemical analysis is present in Table 1.

\subsection{Diffuse Reflectance Fourier Transformed Infrared Spectroscopy (DRIFT)}

Cooled flaxseed samples were ground by coffee grinder (Braun KSM 2), chilled again and re-ground. Grinding was done for 3 min each time. The cooling was done so as to prevent the samples from forming dough and from getting too warm, thus creating artefacts in the spectra. The coffee grinder was selected

Table 1

Biochemical characterization of flaxseed (cv. Vimy): comparison of the raw (control) vs. the treated at various times and temperatures

\begin{tabular}{|c|c|c|c|c|c|}
\hline & \multirow[t]{2}{*}{ Control } & \multicolumn{3}{|c|}{ Treatment } & \multirow[t]{2}{*}{ SEM } \\
\hline & & 1 & 2 & 3 & \\
\hline \multicolumn{6}{|l|}{ Protein profiling } \\
\hline $\mathrm{CP}(\% \mathrm{DM})$ & 23.9 & 23.7 & 23.8 & 23.8 & 0.13 \\
\hline $\mathrm{SCP}(\% \mathrm{DM})$ & $12.4^{\mathrm{a}}$ & $8.5^{\mathrm{b}}$ & $5.4^{\mathrm{c}}$ & $4.5^{\mathrm{c}}$ & 0.32 \\
\hline NPN (\%DM) & $1.4^{\mathrm{b}}$ & $1.3^{\mathrm{b}}$ & $1.5^{\mathrm{b}}$ & $2.0^{\mathrm{a}}$ & 0.10 \\
\hline NDIP (\%DM) & $3.8^{\mathrm{b}}$ & $4.1^{\mathrm{b}}$ & $4.4^{\mathrm{b}}$ & $5.7^{\mathrm{a}}$ & 0.13 \\
\hline ADIP (\%DM) & $0.5^{\mathrm{c}}$ & $0.6^{\mathrm{bc}}$ & $0.7^{\mathrm{ab}}$ & $0.8^{\mathrm{a}}$ & 0.04 \\
\hline \multicolumn{6}{|c|}{ Protein subfractions associated with degradation characteristics } \\
\hline $\mathrm{PA}(\% \mathrm{CP})$ & $6.0^{\mathrm{b}}$ & $5.3^{\mathrm{b}}$ & $6.4^{\mathrm{b}}$ & $8.5^{\mathrm{a}}$ & 0.41 \\
\hline $\mathrm{PB} 1(\% \mathrm{CP})$ & $45.9^{\mathrm{a}}$ & $30.7^{\mathrm{b}}$ & $16.5^{\mathrm{c}}$ & $10.5^{\mathrm{d}}$ & 0.99 \\
\hline $\mathrm{PB} 2(\% \mathrm{CP})$ & $43.0^{\mathrm{c}}$ & $58.3^{\mathrm{b}}$ & $71.0^{\mathrm{a}}$ & $73.3^{\mathrm{a}}$ & 1.09 \\
\hline PB3 $(\% \mathrm{CP})$ & $3.3^{\mathrm{b}}$ & $3.5^{\mathrm{b}}$ & $3.7^{\mathrm{b}}$ & $4.9^{\mathrm{a}}$ & 0.15 \\
\hline $\mathrm{PC}(\% \mathrm{CP})$ & $1.9^{\mathrm{c}}$ & $2.2^{\mathrm{bc}}$ & $2.5^{\mathrm{ab}}$ & $2.8^{\mathrm{a}}$ & 0.11 \\
\hline
\end{tabular}

Notes: ${ }^{\text {a,b,c,d }}$ Means with same superscripts in the same row are not significantly different $(P>0.05)$ LSD method; SEM Standard error of mean. Control - raw; $1-20 \mathrm{~min}, 120^{\circ} \mathrm{C} ; 2-40 \mathrm{~min}, 120^{\circ} \mathrm{C} ; 3-60 \mathrm{~min}, 120^{\circ} \mathrm{C}$. 
to minimize the effects of grinding on the flaxseed spectra ensuring the physical cracking and breaking of the sample yet maintaining as much of the smaller plant seed structures and molecular bonds as possible. Samples of the ground flaxseed were then mixed with $\mathrm{KBr}$ in a ratio of 4 parts flaxseed to 1 part $\mathrm{KBr}$ in a $2 \mathrm{ml}$ centrifuge tube and mixed by vortex for several min. DRIFT was performed using a Bio-Rad FTS-40 with a ceramic IR source and MCT detector (Bio-Rad laboratories, Hercules, CA, USA). Data was collected using Win-IR software. Spectra were generated from the mid-IR $\left(4000-800 \mathrm{~cm}^{-1}\right)$ portion of the electromagnetic spectrum with 256 co-added scans and a spectral resolution of $4 \mathrm{~cm}^{-1}$. Spectral analysis was done with OMNIC 6.0 (Spectra Tech) software.

\subsection{Synchrotron SFTIRM window preparation}

Randomly selected flaxseeds from treatment samples were sectioned to a thickness of $6 \mu \mathrm{m}$ by microtome (Microm 330 (Microm Laborgerate GmbH, Sandhausen, Germany)) at the Western College of Veterinary Medicine, University of Saskatchewan, Canada. The detailed preparation procedure was reported in Walker [15]. Sample sections were subsequently transferred to $\mathrm{BaF}_{2}$ discs (Spectral Systems, NY; part number 915-3015). Each $\mathrm{BaF}_{2}$ disc had 3 separate sections from 3 separate flaxseeds placed on it. Fourteen seeds per treatment were used from each treatment to generate 10 spectra of randomly selected spots within the endosperm of each seed. More spectra were gathered when a collected spectrum contained excessive noise. Figure 1 shows the photomicrograph of cross-section of flaxseed (cv. Vimy) seed showing the intrinsic structure - the epiderm (mucilage) (outside of seed coat), spermoderm (seed coat), endosperm and cotyletons (magnification: $10 \times 20$ ). Picture was taken using Olympus Compound Microscopy with digital camera Model BX41TF, Olympus Optical Co. Ltd.

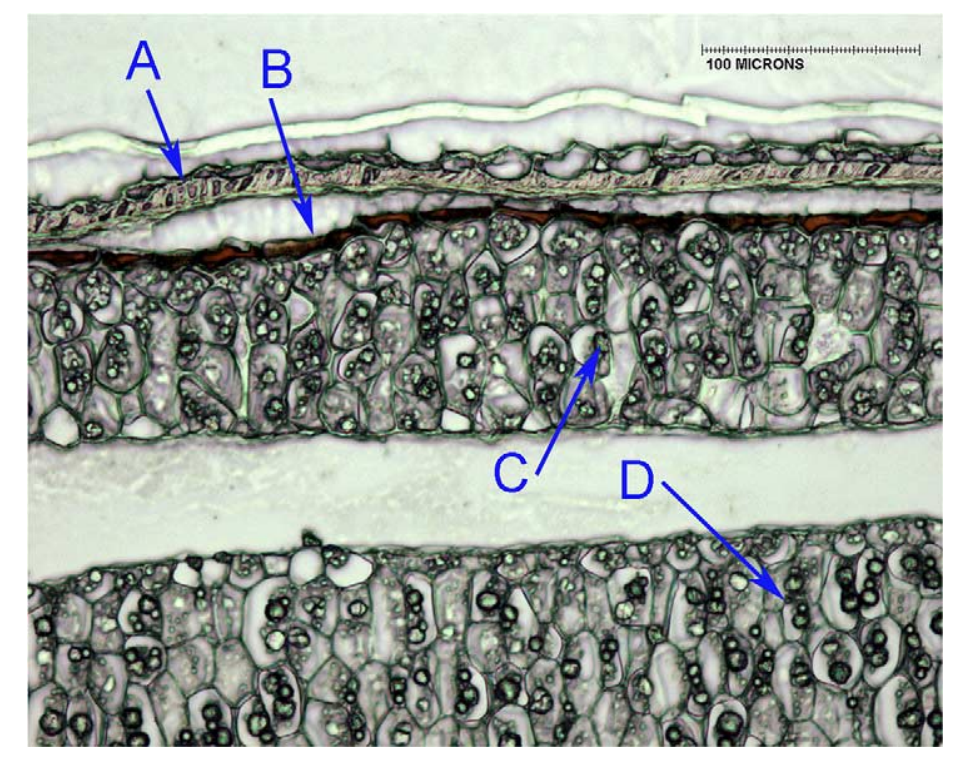

Fig. 1. Photomicrograph of cross-section of flaxseed (cv. Vimy) seed showing the intrinsic structure - (A) the epiderm (mucilage) (outside of seed coat), (B) spermoderm (seed coat), (C) endosperm and (D) cotyletons (magnification: $10 \times 20$ ). (Picture was taken using Olympus Compound Microscopy with digital camera Model BX41TF, Olympus Optical Co. Ltd.) 


\subsection{Synchrotron FTIR microspectroscopy (SFTIRM)}

Synchrotron based FTIR microspectroscopy was performed on beam line U2B at the National Synchrotron Light Source located in Brookhaven National Laboratory (NSLS, BNL, Department of Energy, Upton, NY, USA). Collimated light from the synchrotron was directed to an FTIR spectrometer (Nicolet Magna 860) with a $\mathrm{KBr}$ beam splitter and a nitrogen cooled mercury cadmium telluride (MCT-A) detector through a port on the spectrometer. The spectrometer was interfaced with a Nic PLAN IR microscope using a single image plane mask set to give an aperture of $10 \mu \mathrm{m} \times 10 \mu \mathrm{m}$. Spectra were generated in transmission mode with the mid-IR $\left(4000-800 \mathrm{~cm}^{-1}\right)$ portion of the electromagnetic spectrum by 128 co-added scans with a spectral resolution of $4 \mathrm{~cm}^{-1}$. Spectral analysis was done with OMNIC 6.0 (Thermo-Nicolet, Madison, WI, USA) software. Spectra were generated from randomly selected regions of the endosperm of the flaxseed sections.

\section{6. $\alpha$-helix to $\beta$-sheet ratio measurement}

Protein secondary structures were estimated using the amide I functional group band located in the region of ca. $1700-1610 \mathrm{~cm}^{-1}$. Two different methods were used to estimate relative protein secondary structure concentrations for DRIFT spectra. In the first method the spectra were first converted by Fourier self-deconvolution with OMNIC 6.0 (Spectra Tech., USA) to identify the component peaks and frequencies that comprise the amide I band. The area of the component bands representing $\alpha$-helices and $\beta$-sheets in the FSD spectra were then calculated using Origin data analysis software (Origin Lab Corporation, Northampton, MA, USA) with both the Gaussian and Lorentzian multi component peak modeling methods. The area under the peak at ca. $1658 \mathrm{~cm}^{-1}$ was taken to represent amide I bonds in the $\alpha$-helical conformation while the area under the peak at ca. $1630 \mathrm{~cm}^{-1}$ was the amide I bonds in the $\beta$-sheet conformation. The second method was used for both DRIFT and SFTIRM spectra and involved using the FSD spectra generated with OMNIC 6.0 to identify the region of the absorption spectra representing the respective secondary structures. OMNIC 6.0 was then used to calculate the area in the absorption spectra representing the $\alpha$-helices and $\beta$-sheets.

\subsection{Multivariate analysis of protein spectra}

CLA and PCA multivariate statistical methods were used to compare the DRIFT spectra of the different treatments to the control samples to determine if there were some underlying structural differences in the spectral information that would permit the identification of spectra belonging to different treatment groups. First the absorbance spectra were baseline corrected using the automatic baseline correction function of OMNIC 6.0. The spectra were then analyzed together using Statistica 6.0 software (Statsoft, Tulsa, OK, USA). For CLA and PCA the spectral regions of $2000-800 \mathrm{~cm}^{-1}$, containing most of the mid-IR spectrum, and $1715-1485 \mathrm{~cm}^{-1}$, containing the amide I and II regions, were used. CLA results were presented as dendograms while PCA results were plotted based on the two highest factor scores and plotted as a function of those scores. In each comparison the eigenvector for factor 1 was plotted against that for factor 2 which accounted for over $99 \%$ of the variability in the data.

\subsection{Statistical analysis}

Statistical analyses of protein secondary structure ratios were performed using the MIXED procedure of SAS (version 9.1). DRIFT spectra were analyzed in a completely randomized design using the model: $Y=$ mean + treatment + error. 
SFTIRM spectra were analyzed in a nested experimental design with the model: $Y=$ mean + treatment + seed (nested within treatment) + error. Significance was taken as $P<0.05$.

\section{Results and discussion}

Results from the protein secondary structure analysis based on the DRIFT spectra are presented in Table 2. It is important to note that these ratios are based on relative values of the secondary structures present. Using an $\alpha$-helix to $\beta$-sheet ratio to assess changes to protein requires many considerations. From IR spectroscopy, it may not be possible to get exact values for each secondary structure, but if all sample spectra are treated in the same manner, we can compare the results from one treatment to another [19]. In addition to this, because of different methodologies used between researchers, results from one study can be different from another considering the same biological tissue. This arises from the complexity of the information contained within the mid-IR spectrum. Selecting different regions of the spectrum and different sizes for those regions around the amide I and II bands along with different baselines are all factors that would influence the resulting $\alpha$-helix to $\beta$-sheet ratio [19]. There exists technical issues that affect protein secondary structure analysis as well. The amide I band carbonyl group has different sensitivities to absorption depending on secondary structure, the number of bands it contains varies and is usually not known for certain, and finally the bands can be varied in shape [19]. Even for relative determinations of the $\alpha$-helix to $\beta$-sheet ratio we must be aware of these facts. Despite these issues the $\alpha$-helix to $\beta$-sheet ratio can be a useful way of exploring differences in protein structure that exist between treatments and varieties.

What is clear in all three ratio measurements is that the ratio of $\alpha$-helices to $\beta$-sheets decreased significantly upon heating $(P<0.05)$ (Table 2$)$. This change is in accordance with those published by Yu et al. [23] using golden flaxseed and the SFTIRM technique with roasting as heating method. Of the three methods used to estimate the relative $\alpha$-helix to $\beta$-sheet ratios only the area under peak method was able to discern any difference between the treatments (Table 3 ). These changes in the protein secondary structure ratio are likely due to more $\alpha$-helices being denatured or destroyed during the autoclaving process than $\beta$-sheets. These estimates however seem to disagree with results published by Madhusudhan and Singh $[7,8]$ who reported that the major proteins of flaxseed, albumin and globulin, consist predominantly of $\beta$-sheet secondary structures as determined by the circular dichroism (CD) technique using purified protein samples. It is possible, however, that the remaining $14 \%$ of protein in flaxseed outside these two classes have extremely high concentrations of $\alpha$-helices relative to other secondary structure types. It should also be noted that there is some degree of variability in terms of oil and protein content for varieties, growing conditions are also known to affect content as well, which means the differences in the reported values could be explained in this manner.

In Table 3 the results of the same analysis are shown for S-FTIR data. The $\alpha$-helix to $\beta$-sheet ratio increased upon heating which differed from the DRIFT results. The control sample and the $20 \mathrm{~min}$ autoclave treatment were not significantly different from one another as was the case for the $40 \mathrm{~min}$ and $60 \mathrm{~min}$ treatment samples. One possibility for the difference in the effect autoclaving has on the $\alpha$-helix to $\beta$-sheet ratio between the two mid-IR spectroscopic methods is that DRIFT spectra were from whole flaxseeds which includes the seed coat, pericarp, aleurone layer and endosperm (Fig. 1). The aleurone layer is rich in protein and its composition may be different from that of the endosperm. The synchrotron SFTIRM spectra on the other hand were generated solely from the endosperm region of the flaxseed. Furthermore, it is possible that the individual regions may have different sensitivities to heating which 
Table 2

$\alpha$-helix to $\beta$-sheet ratios from DRIFT spectra of the autoclaved Vimy flaxseed

\begin{tabular}{lccccr}
\hline & Control & \multicolumn{3}{c}{ Treatment } & \multicolumn{2}{c}{ SEM } \\
\cline { 3 - 5 } & & 1 & 2 & 3 & \\
\hline DRIFT method (area under peak method) & $2.18^{\mathrm{a}}$ & $1.60^{\mathrm{b}}$ & $1.27^{\mathrm{c}}$ & $1.37^{\mathrm{c}}$ & 0.011 \\
Gaussian modeling & $2.08^{\mathrm{a}}$ & $1.06^{\mathrm{b}}$ & $0.99^{\mathrm{b}}$ & $1.23^{\mathrm{b}}$ & 0.072 \\
Lorentzian modeling & $2.27^{\mathrm{a}}$ & $1.07^{\mathrm{b}}$ & $1.10^{\mathrm{b}}$ & $1.72^{\mathrm{ab}}$ & 0.071 \\
\hline
\end{tabular}

Notes: ${ }^{\text {a,b,c }}$ Means with same superscripts in the same row are not significantly different $(P>0.05)$. Means separated using the LSD method. Control - raw; $1-20 \mathrm{~min}, 120^{\circ} \mathrm{C} ; 2-40 \mathrm{~min}, 120^{\circ} \mathrm{C} ; 3-60 \mathrm{~min}, 120^{\circ} \mathrm{C}$.

Table 3

$\alpha$-helix to $\beta$-sheet ratios in the endosperm area of the autoclaved flaxseed as determined using the area under peak method and synchrotron SFTIRM data

\begin{tabular}{lccccc}
\hline & Control & \multicolumn{3}{c}{ Treatment } & SEM \\
\cline { 3 - 5 } & & 1 & 2 & 3 & \\
\hline SFTIRM method (area under peak method) & $0.86^{\mathrm{b}}$ & $0.88^{\mathrm{b}}$ & $1.03^{\mathrm{a}}$ & $1.03^{\mathrm{a}}$ & 0.003 \\
\hline
\end{tabular}

Notes: ${ }^{\mathrm{a}, \mathrm{b}}$ Means with same superscripts in the same row are not significantly different $(P>0.05)$. Means separated using the LSD method. Control - raw; $1-20 \mathrm{~min}, 120^{\circ} \mathrm{C} ; 2-40 \mathrm{~min}, 120^{\circ} \mathrm{C} ; 3-60 \mathrm{~min}, 120^{\circ} \mathrm{C}$.

may cause different changes to secondary structure ratios to different flaxseed tissues. Further study is required to understand the effect of heating on different tissues within flaxseed.

Figure 2 shows the results of cluster analysis for the ca. $2000-800 \mathrm{~cm}^{-1}$ spectral region based on DRIFT spectra. Other than a single spectrum from the 20 min autoclaved treatment 1 , the raw spectra are isolated in their own cluster. The remaining clusters all contain combinations of spectra from the other treatments. This implies that DRIFT spectroscopy combined with cluster analysis can distinguish autoclaved flaxseed samples from the raw samples and the benefit of cluster analysis is that no other prior knowledge of the sample other than a mid-IR spectrum is required to make such a distinction. The cluster analysis comparisons show similar results to those displayed in Fig. 3. Comparison between the control spectra and treatment 1 spectra as shown in Fig. 3a. Here a single spectrum from treatment 1 is clustered among the control samples. In Fig. $3 \mathrm{~b}$ the treatment 2 spectra and the control spectra are all found within distinct clusters although the dendogram shows that some of the treatment 2 spectra are more closely related to the control spectra. Figure $3 \mathrm{c}$ shows a very clear separation between the control spectra and treatment 3 spectra with all spectra falling within their respective clusters. Figure $3 \mathrm{~d}$ shows a distinct cluster for the treatment 2 spectra, however, not all the spectra from treatment 2 were similar enough to be assigned to this group. The remaining CLA comparisons (Fig. 3e, f) failed to demonstrate any distinct groupings among the treatments.

Figure 4 shows the results of the principal components analysis conducted using DRIFT spectra. The results show a similar grouping of the raw flaxseed spectra with a single spectrum from the 20 min autoclaved treatment 1 . The agreement of both PCA and cluster analyses suggests that there is some similar structure in the data, in this case the baseline corrected spectra, which distinguishes almost completely the raw sample spectra from those spectra of autoclaved samples. The plot was derived from values for the first two principal components generated by the analysis which explain $95.88 \%$ and $3.42 \%$ of the variability in the spectra. Factor 1 in this case can almost discriminate entirely between the raw and treated flaxseed samples and represents the vast majority of the variability present. As in the case for cluster analysis, Yu et al. [20] showed that PCA could also distinguish between plant structures. We 


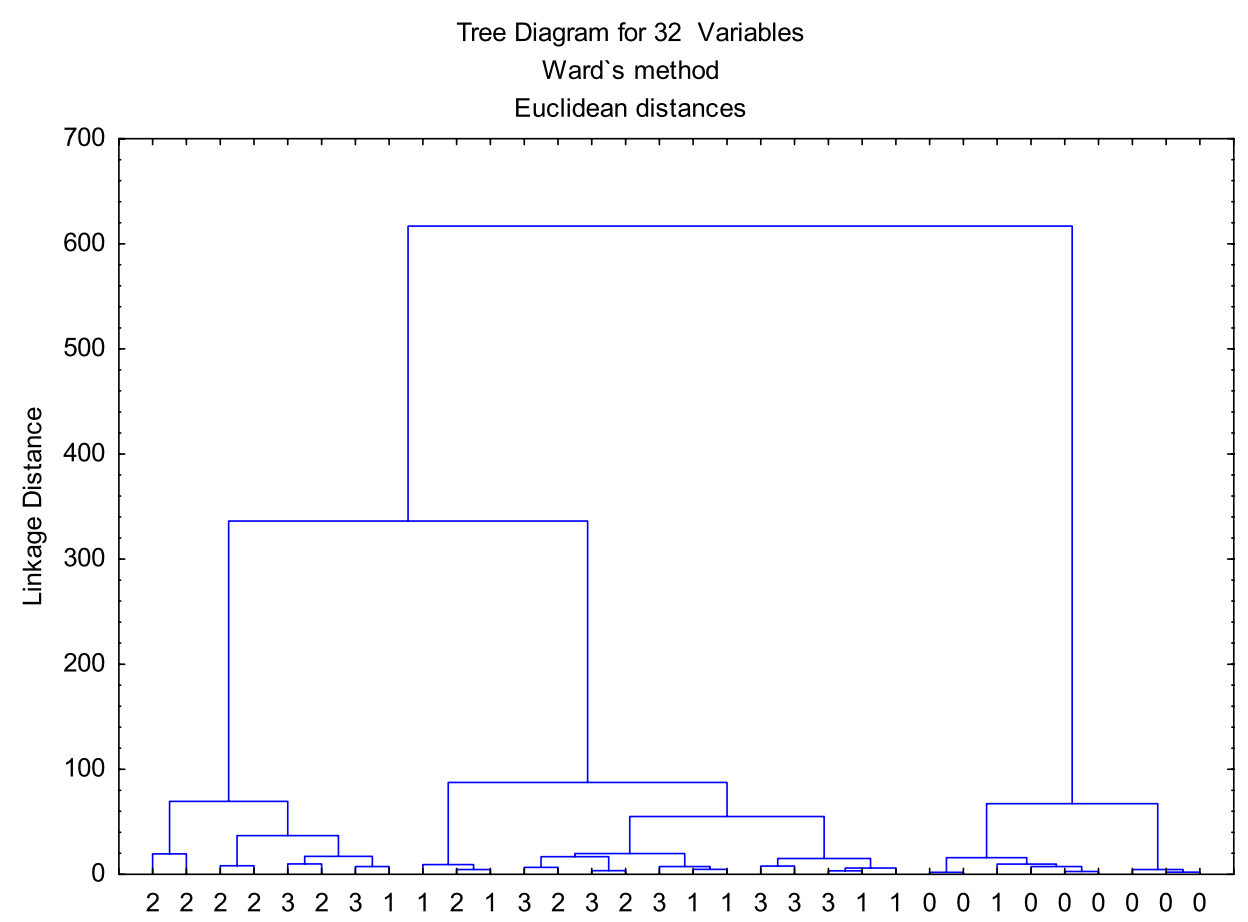

Fig. 2. CLA analysis of DRIFT based spectra $\left(2000-800 \mathrm{~cm}^{-1}\right)$ obtained from the raw and the autoclaved flaxseed samples $\left(0-\right.$ control/raw, $1-120^{\circ} \mathrm{C}$ for $20 \mathrm{~min}, 2-120^{\circ} \mathrm{C}$ for $40 \mathrm{~min}, 3-120^{\circ} \mathrm{C}$ for $\left.60 \mathrm{~min}\right)$. (CLA - Hierarchical cluster analysis, DRIFT - Diffuse Reflectance Infrared Fourier Transform.)

can conclude that not only can we use FTIR based experimental methods with little modification to the spectra to identify treated samples but also to identify which part of the plant the spectra were derived.

Further PCA spectral comparisons are shown in Fig. 5. Figure 5a shows the results from PCA between the control and the treatment 1 spectra. Similar to the CLA results Fig. 5a shows that a single spectrum from the first treatment is indistinguishable from the control samples. In Fig. 5b and c, the control spectra are found in their own group with treatment spectra spread out more but not mixed up in the areas occupied by control spectra. This shows a bit of distinction from the CLA results for the treatment 2 spectra where there was still some linkage to the control samples. The remaining spectral comparisons (Fig. 5d-f) by PCA were not able to show any clear grouping of the spectra on the factor plane.

CLA and PCA were subsequently conducted on a more defined region of the spectrum, in this case the spectrum from ca. $1715-1485 \mathrm{~cm}^{-1}$ which covered both the prominent amide I and II bands. Figure 6 shows the CLA results from this region of the spectrum for all treatment spectra. It shows a similar cluster pattern to that in Fig. 2 with the exception that in it there is a distinct cluster for the treatment 2 spectra although not all of the treatment 2 spectra are contained within it. It also shows that the control samples are found in their own group with a single spectrum from treatment 1. Figure 7b shows CLA results for the treatment 2 to control spectral comparison. This analysis shows an improvement of the clustering ability when we narrowed the spectral window, in this case both the control spectra and the treatment 2 spectra are found in their own unique clusters as opposed to when a much larger portion of the spectrum were used. This indicates that the protein structures were different between raw flaxseed and that from treatment 2 , this is similar to the results between raw flaxseed and that from treatment 3 . This 

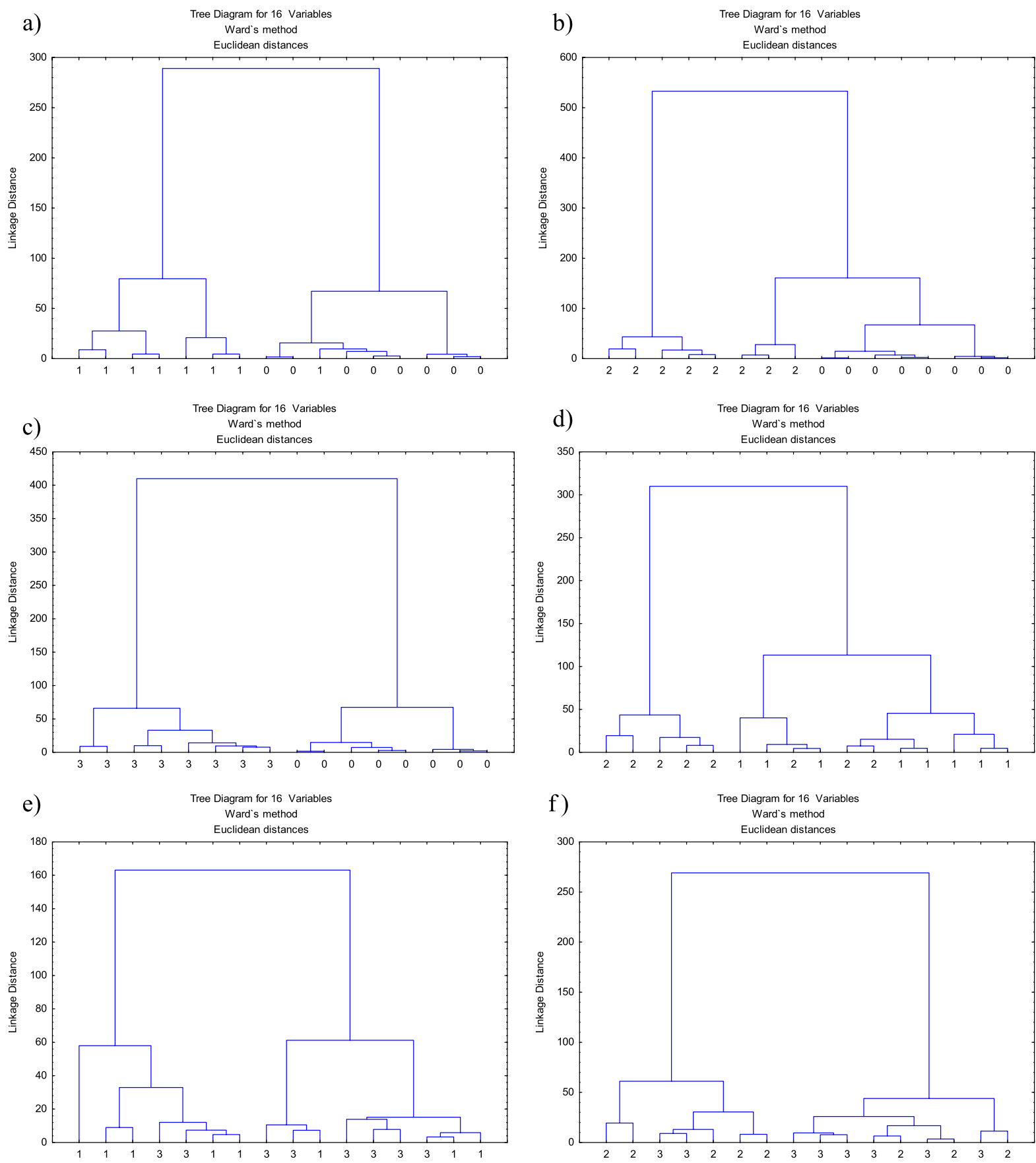

Fig. 3. CLA analysis of DRIFT based spectra $\left(2000-800 \mathrm{~cm}^{-1}\right)$ obtained from the raw and the autoclaved flaxseed samples. Comparisons of the separate treatments ( $\mathrm{a}-0$ vs. $1, \mathrm{~b}-0$ vs. $2, \mathrm{c}-0$ vs. $3, \mathrm{~d}-1$ vs. $2, \mathrm{e}-1$ vs. $3, \mathrm{f}-2$ vs. 3$) ;(0-$ control/raw, $1-120^{\circ} \mathrm{C}$ for $20 \mathrm{~min}, 2-120^{\circ} \mathrm{C}$ for $40 \mathrm{~min}, 3-120^{\circ} \mathrm{C}$ for $60 \mathrm{~min}$ ). (CLA - Hierarchical cluster analysis, DRIFT - Diffuse Reflectance Infrared Fourier Transform.) 


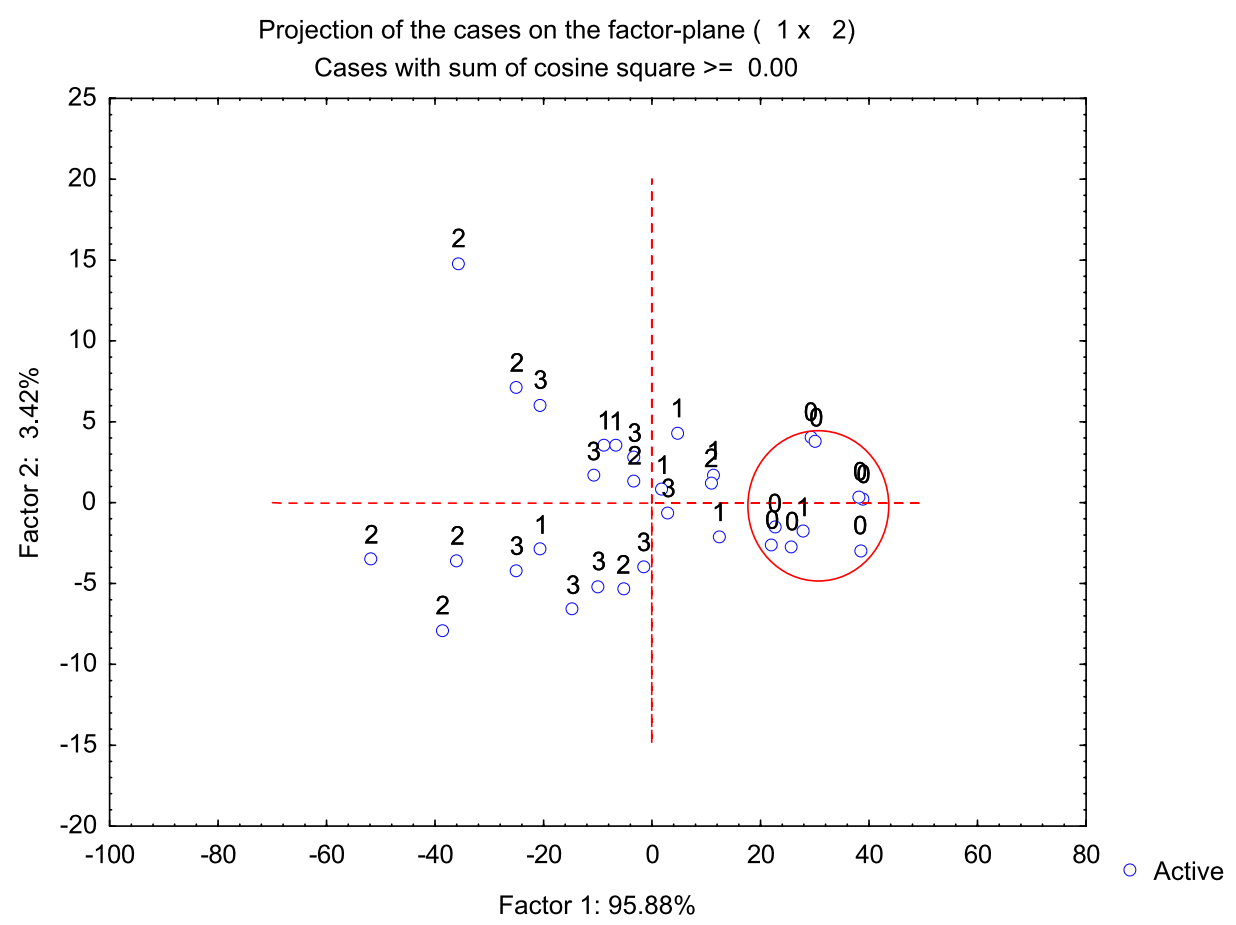

Fig. 4. PCA analysis of DRIFT based spectra $\left(2000-800 \mathrm{~cm}^{-1}\right)$ obtained from the raw and the autoclaved flaxseed samples $\left(0\right.$ - control/raw, $1-120^{\circ} \mathrm{C}$ for $20 \mathrm{~min}, 2-120^{\circ} \mathrm{C}$ for $40 \mathrm{~min}, 3-120^{\circ} \mathrm{C}$ for $60 \mathrm{~min}$ ). (PCA - Principal components analysis, DRIFT - Diffuse Reflectance Infrared Fourier Transform.)

improvement in clustering is also seen in Fig. $7 \mathrm{f}$ where we find clusters for treatments 2 and 3 although there still remains some mixing of the spectra in the remaining clusters.

The PCA analysis shows similar improvements upon selecting a smaller spectral window. In Fig. 8 where all spectra are included in a PCA there is no longer a spectrum from the treatment 1 group present amongst the control sample spectra. Upon further examination of the comparisons between the treatments shown in Fig. 9a-c we can see that autoclaved treatments are completely separated from the raw spectra. The separation indicated that treatment spectra differ from the raw spectra and suggested that there was a molecular structure change in the protein based on the amide I and amide II regions.

While it appears as though more work is required to establish how we can use protein secondary structures to forecast degradability of a feed after a given treatment, these changes are the result of autoclave treatment and cooking in general [2] which will influence degradability. It may be that the two primary secondary structures need to be supplemented with information about other secondary structures such as random coils to use this measure more accurately in predicting degradability. It is also evident that there needs to be a standardized and well controlled procedure for sample preparation as demonstrated by the difference in the relative ratios of $\alpha$-helices to $\beta$-sheets as measured by multiple techniques using both DRIFT and S-FTIR.

It could be erroneous to rely solely on protein secondary structure ratios to predict digestibility. It has been shown that feathers are poorly degradable protein sources and are rich in beta sheets [22]. This, however, should not preclude feeds that are low in $\alpha$-helices and high in $\beta$-sheets from being rapidly degraded in the rumen as the $\beta$-keratins that make up the feather have other molecular properties 
a)
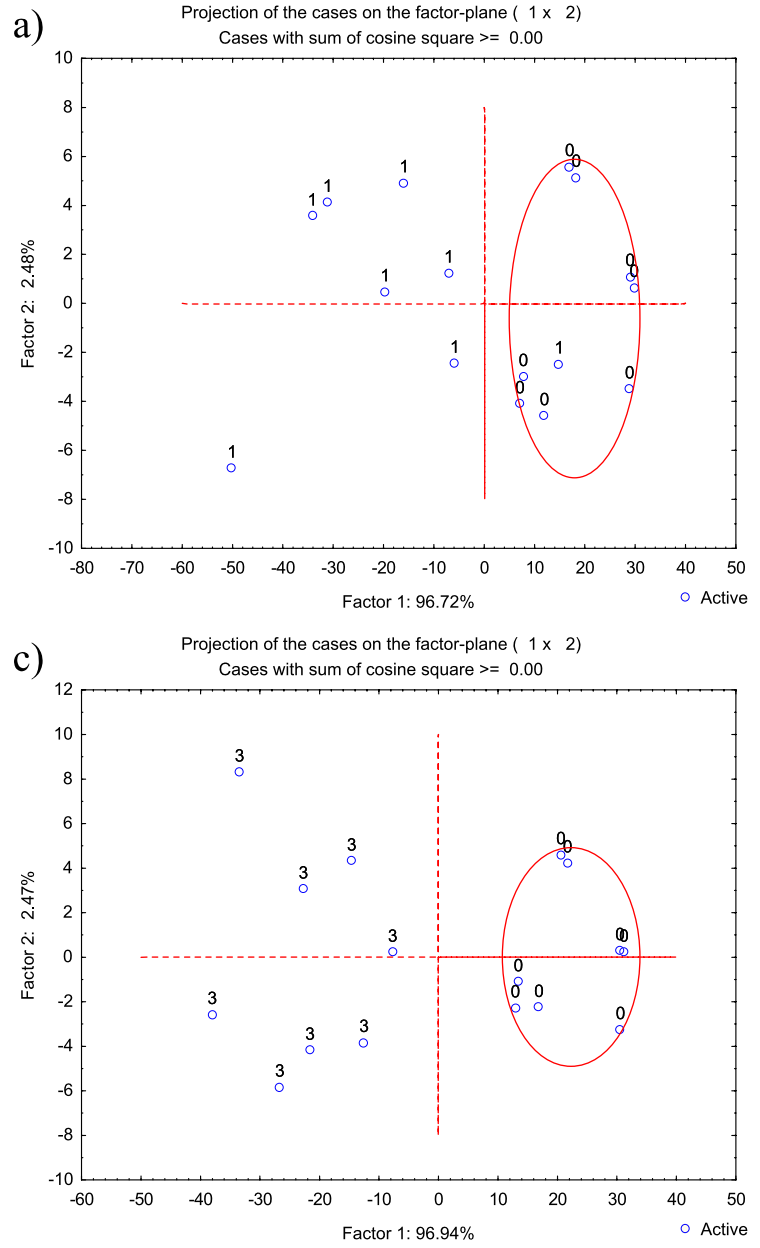

e)

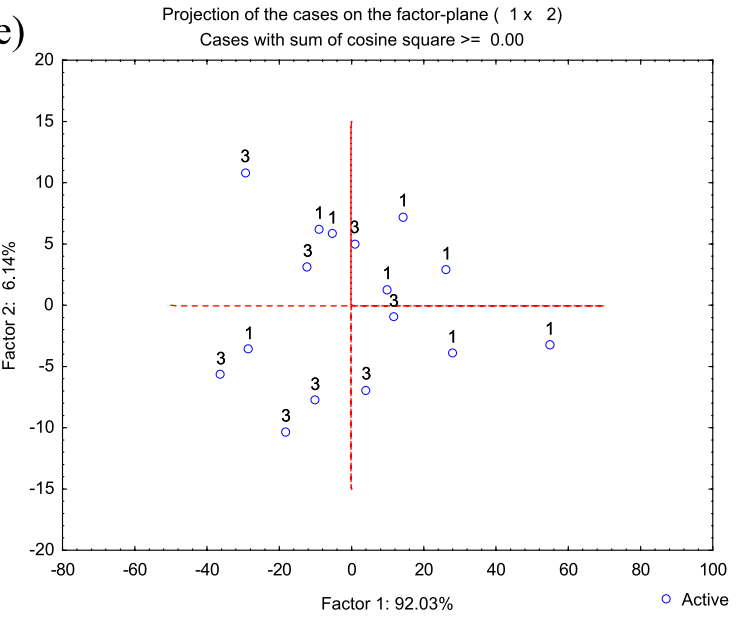

b) Projection of the cases on the factor-plane $\left(\begin{array}{ll}1 \times & 2\end{array}\right)$

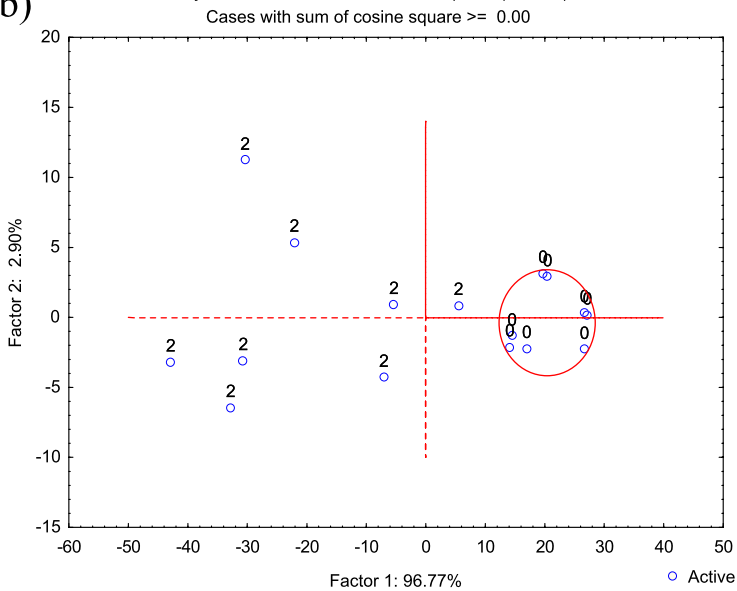

d)
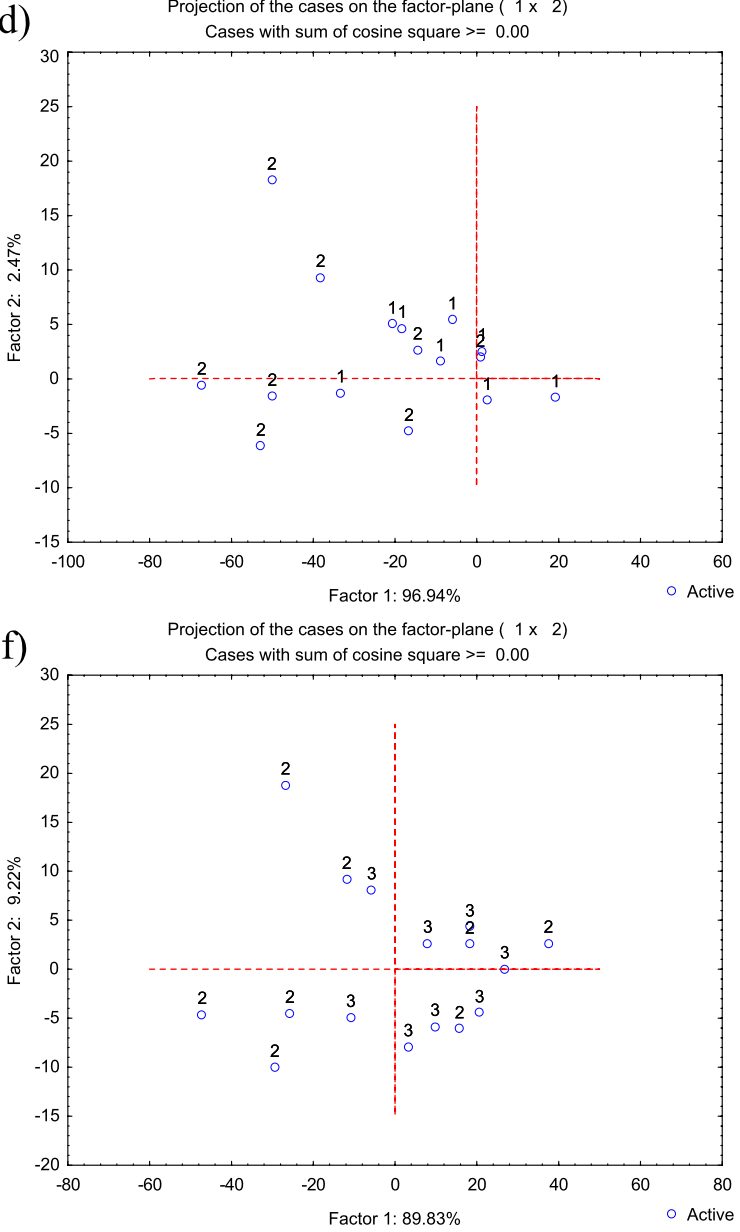

Fig. 5. PCA analysis of DRIFT based spectra $\left(2000-800 \mathrm{~cm}^{-1}\right)$ obtained from the raw and the autoclaved flaxseed samples. Comparisons of the separate treatments ( $\mathrm{a}-0$ vs. $1, \mathrm{~b}-0$ vs. 2 , c -0 vs. $3, \mathrm{~d}-1$ vs. 2 , e -1 vs. 3 , f -2 vs. 3 ); $(0-\mathrm{control} / \mathrm{raw}$, $1-120^{\circ} \mathrm{C}$ for $20 \mathrm{~min}, 2-120^{\circ} \mathrm{C}$ for $40 \mathrm{~min}, 3-120^{\circ} \mathrm{C}$ for $60 \mathrm{~min}$ ). (PCA - Principal components analysis, DRIFT - Diffuse Reflectance Infrared Fourier Transform.) 


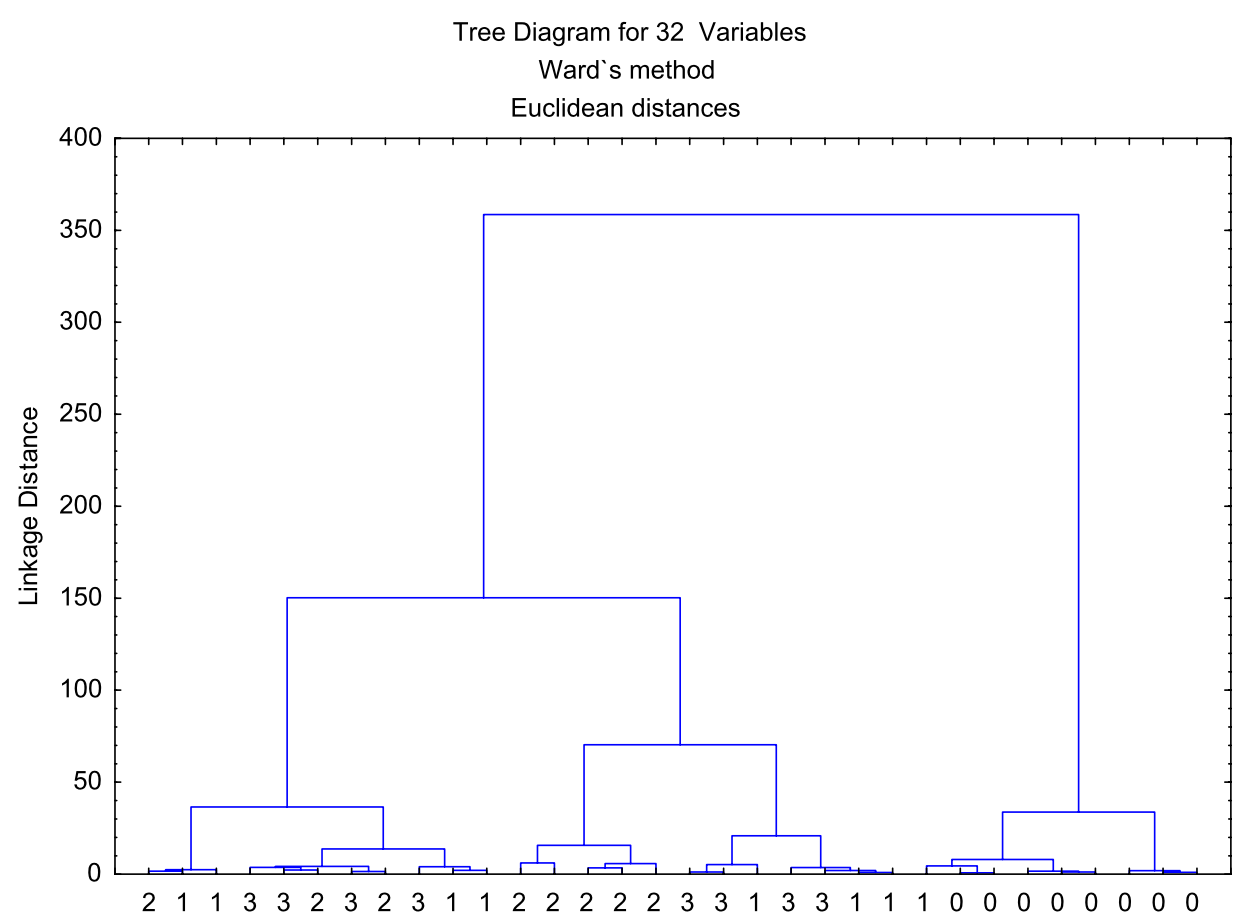

Fig. 6. CLA analysis of DRIFT based spectra of the amide I and II region (1715-1485 $\mathrm{cm}^{-1}$ ) obtained from the raw and the autoclaved flaxseed samples $\left(0-\right.$ control/raw, $1-120^{\circ} \mathrm{C}$ for $20 \mathrm{~min}, 2-120^{\circ} \mathrm{C}$ for $40 \mathrm{~min}, 3-120^{\circ} \mathrm{C}$ for $\left.60 \mathrm{~min}\right)$. (CLA Hierarchical cluster analysis, DRIFT - Diffuse Reflectance Infrared Fourier Transform.)

rendering them insoluble and poorly degraded such as a high concentration of disulfide bonds. Hair is made up of $\alpha$-keratin which is high in $\alpha$-helices and cystein bonds. Hair, like feathers, has been shown to be poorly degraded as well [14]. Further investigation into the digestibility and molecular chemistry of these two poorly degraded proteins may provide some insight into how secondary structure influences degradability.

Comparisons of protein secondary structure ratios for other feed sources may only be applicable when dealing with a single variety within the same genus and species. Even when considering the same variety, growing conditions and even topography have the capacity to alter protein content of plants [5]. Changes to protein quality will be reflected by different amounts of the various storage proteins specific to each plant [11] which means that the initial $\alpha$-helix to $\beta$-sheet ratio could be altered by these conditions and after processing may show different shifts to secondary structures as a result.

The results from the multivariate statistical methods used in this study show that by focusing in on specific regions of the spectrum we can enhance our ability to segregate the spectra based on treatment conditions. This is likely a result of eliminating some extraneous data that bogs down the analysis or, in the case of autoclaving, data for peaks that are minimally influenced by the treatment. In IR spectra a large region, found between ca. $2500-2000 \mathrm{~cm}^{-1}$, is usually devoid of any peaks of interest so removing data contained in regions such as these from the analysis is justifiable. Selecting windows or regions of the spectra will also allow us to determine which regions, representing certain molecules, are more or less affected by a given treatment.

For multivariate analyses very little modification of the spectra and thus very little time is required for this analysis. The implications of this are that with a pool of spectra we would only need to add 

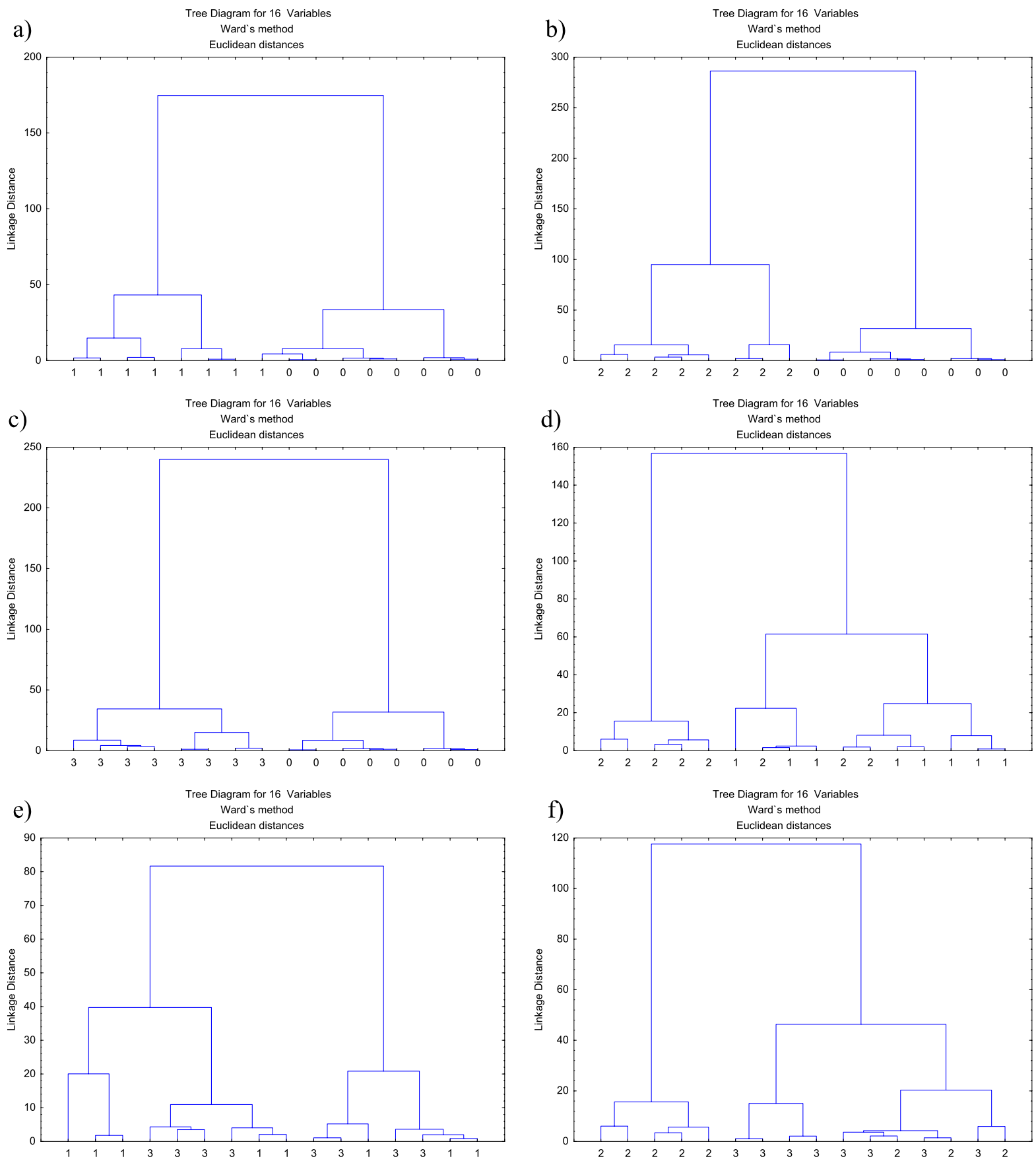

Fig. 7. CLA analysis of DRIFT based spectra of the amide I and II region (1715-1485 $\left.\mathrm{cm}^{-1}\right)$ obtained from the raw and the autoclaved flaxseed samples. Comparisons of the separate treatments ( -0 vs. $1, b-0$ vs. $2, \mathrm{c}-0$ vs. 3 , d -1 vs. 2 , e -1 vs. 3 , f - 2 vs. 3 ); $\left(0-\right.$ control/raw, $1-120^{\circ} \mathrm{C}$ for $20 \mathrm{~min}, 2-120^{\circ} \mathrm{C}$ for $40 \mathrm{~min}, 3-120^{\circ} \mathrm{C}$ for $\left.60 \mathrm{~min}\right)$. (CLA - Hierarchical cluster analysis, DRIFT - Diffuse Reflectance Infrared Fourier Transform.) 


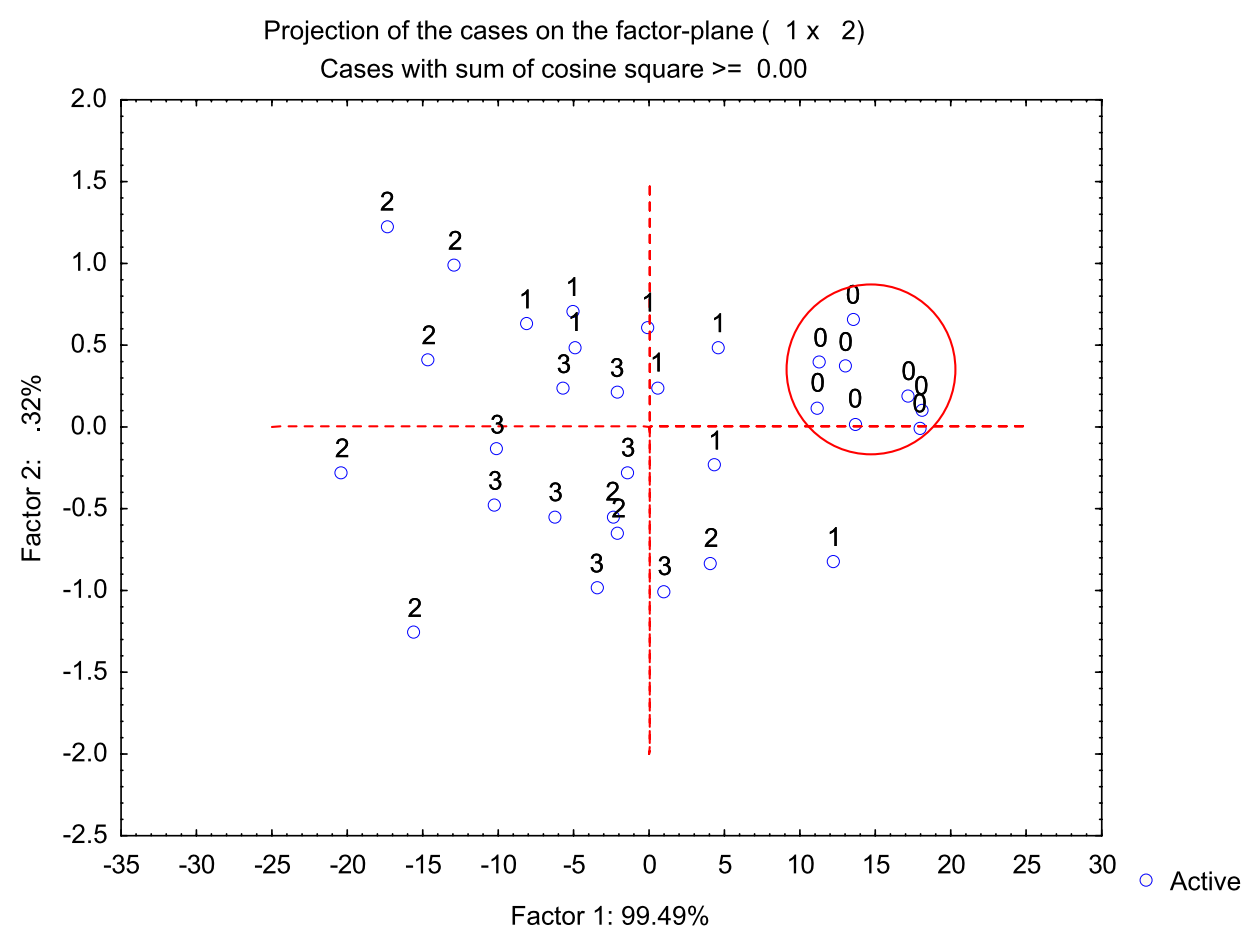

Fig. 8. PCA analysis of DRIFT based spectra for the amide I and II region $\left(1715-1485 \mathrm{~cm}^{-1}\right)$ obtained from the raw and the autoclaved flaxseed samples $\left(0-\right.$ control/raw, $1-120^{\circ} \mathrm{C}$ for $20 \mathrm{~min}, 2-120^{\circ} \mathrm{C}$ for $40 \mathrm{~min}, 3-120^{\circ} \mathrm{C}$ for $\left.60 \mathrm{~min}\right)$. (PCA Principal components analysis, DRIFT - Diffuse Reflectance Infrared Fourier Transform.)

an unknown spectrum of interest to the cluster analysis procedure to discover if the sample has been autoclaved or not, provided all other things remain equal such as sample preparation. The $20 \mathrm{~min}$ autoclave procedure is a relatively mild treatment so the ability to make this distinction is indicative of the potential of this methodology. These results are further validated by those reported by Yu et al. [20] where using S-FTIR spectra and also without prior modifications of the spectra cluster analysis was able to distinguish between those spectra from various wheat structures such as endosperm and the aleurone layer.

\section{Conclusions and implications}

The multivariate spectral analyses employed in this experiment showed that, in terms of classification, they can provide a clear impact of treatment through association to the treatment conditions [4]. Linking these results to degradability itself rather than treatment conditions might prove to be a more effective way of using these statistical tools for this sort of comparison. Similar FTIR methodologies have been used to identify bacteria in the past classifying different strains of the same genus [9]. This work indicates that there is a vast potential for FTIR whether DRIFT or S-FTIR based spectroscopies are employed in the food/feed industry. Further investigation into the influence of protein secondary structure in relation to degradability and digestibility is required. 
a)

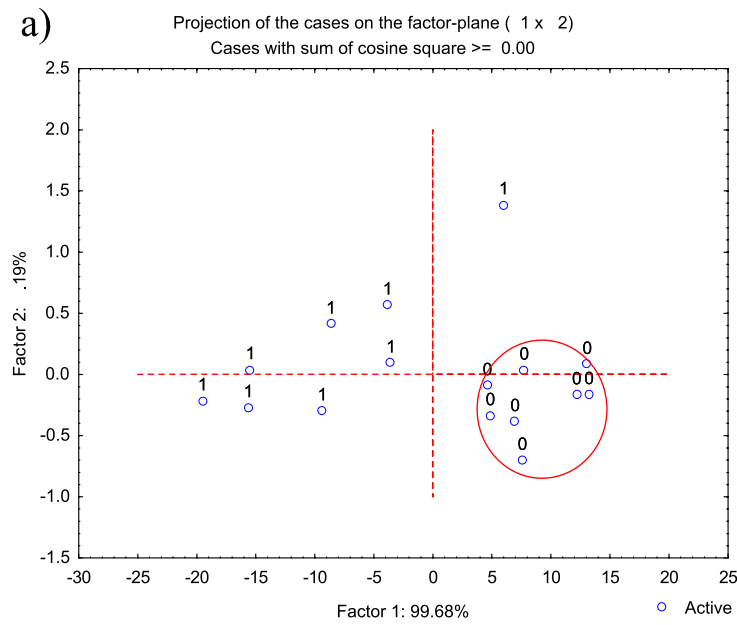

c)

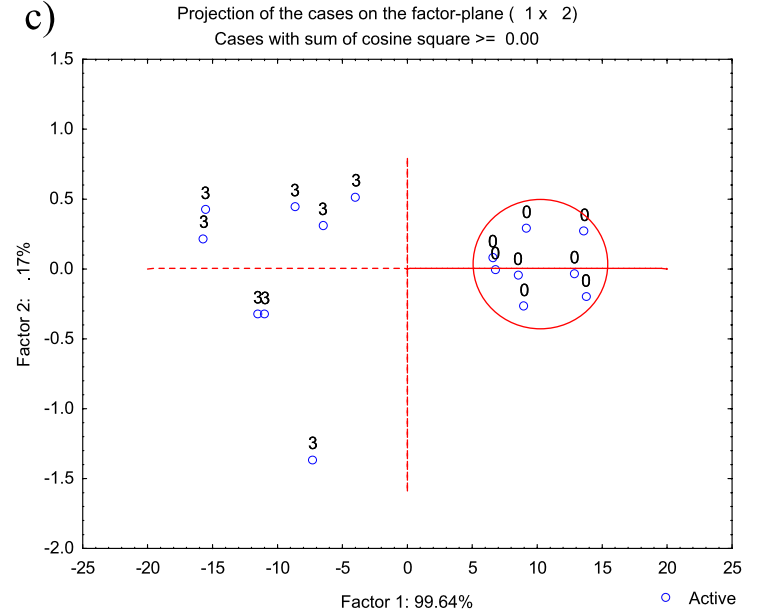

e)

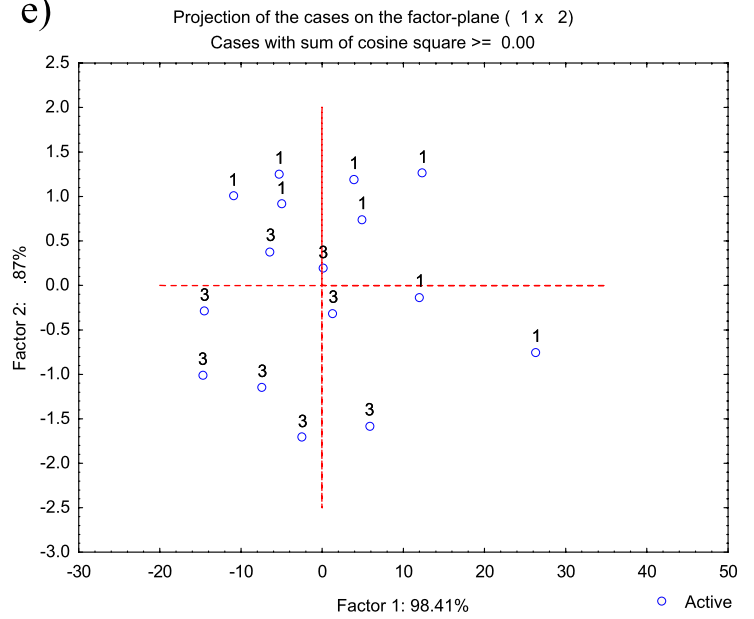

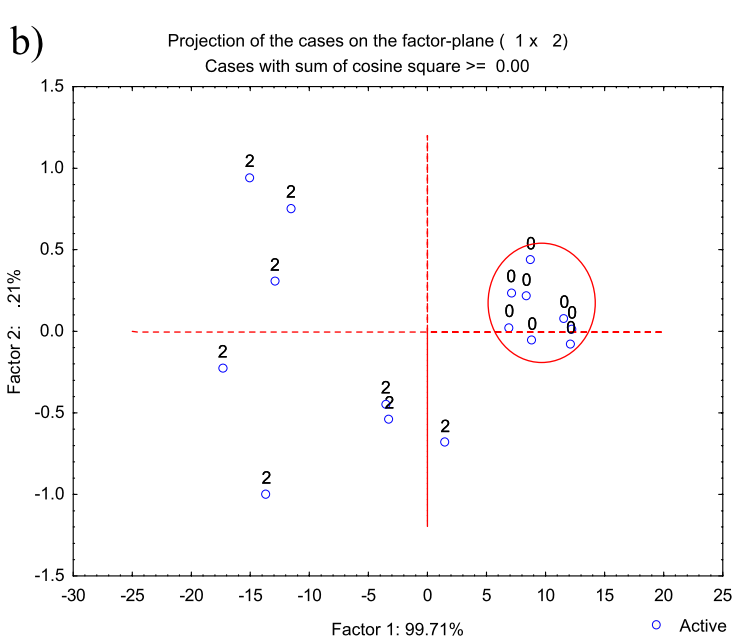

d) Projection of the cases on the factor-plane $\left(\begin{array}{ll}1 \times 2 & 2\end{array}\right)$
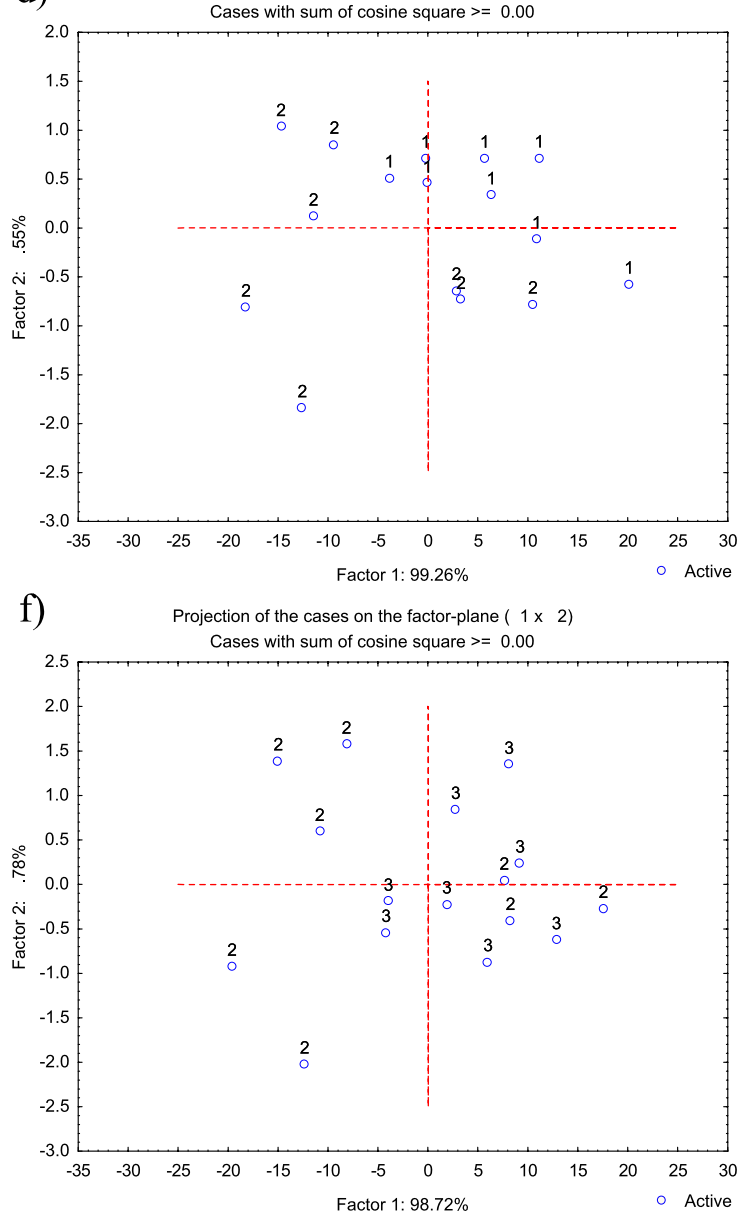

Fig. 9. PCA analysis of DRIFT based spectra for the amide I and II region $\left(1715-1485 \mathrm{~cm}^{-1}\right)$ obtained from the raw and the autoclaved flaxseed samples. Comparisons of the separate treatments (a-0 vs. $1, b-0$ vs. $2, \mathrm{c}-0$ vs. $3, \mathrm{~d}-1$ vs. 2 , e -1 vs. 3 , f -2 vs. 3); ( 0 - control/raw, $1-120^{\circ} \mathrm{C}$ for $20 \mathrm{~min}, 2-120^{\circ} \mathrm{C}$ for $40 \mathrm{~min}, 3-120^{\circ} \mathrm{C}$ for $60 \mathrm{~min}$ ). (PCA - Principal components analysis, DRIFT - Diffuse Reflectance Infrared Fourier Transform.) 


\section{References}

[1] AOAC, Official Methods of Analysis, Association of Official Analytical Chemists, Washington, DC, 1990.

[2] A. Arnoldie, Thermal processing and food quality: Analysis and control, in: Thermal Technologies in Food Processing, P. Richardson, ed., Woodhead, Cambridge, 2001, pp. 138-159.

[3] B.O. Budevska, Applications of vibrational spectroscopy in life, pharmaceutical and natural sciences, in: Handbook of Vibrational Spectroscopy, Vol. 5, J.M. Chalmers and P.R. Griffiths, eds, Wiley, New York, 2002, pp. 3720-3732.

[4] K.J. Doiron, P. Yu, J.J. McKinnon and D.A. Christensen, Heat-induced protein structures and protein subfractions in relation to protein degradation kinetics and intestinal availability in dairy cattle, J. Dairy Sci. 92 (2009), 3319-3330.

[5] A.N. Kravchenko and D.G. Bullock, Variability of soybean quality data as a function of field topography: I. Spatial data analysis, Crop Sci. 42 (2002), 804-815.

[6] G. Licitra, T.M. Hernandez and P.J. Van Soest, Standardization of procedures for nitrogen fractionation of ruminant feeds, Anim. Feed Sci. Technol. 57 (1996), 347-358.

[7] K.T. Madhusudhan and N. Singh, Isolation and characterization of the major fraction (12 S) of linseed proteins, J. Agric. Food Chem. 33 (1985), 673-677.

[8] K.T. Madhusudhan and N. Singh, Isolation and characterization of a small molecular weight protein of linseed meal, Phytochem. 24 (1985), 2507-2509.

[9] K. Maquelin, C. Kirschner, L.P. Choo-Smith, N. Van den Braak, H.P. Endtz, D. Naumann and G.J. Puppels, Identification of medically relevant microorganisms by vibrational spectroscopy, J. Microbiological Methods 51 (2002), 255-271.

[10] V.B. Novikov, A.A. Stolov, V.V. Gorbatchuk and B.N. Solomonov, Solvent effects on infrared spectroscopic and calorimetric characteristics of aliphatic ketones in binary solvent mixtures, J. Phys. Org. Chem. 11 (1998), 283-289.

[11] N.C. Paek, J. Imsande, R.C. Shoemaker and R. Shibles, Nutritional control of soybean seed storage protein, Crop Sci. 37 (1997), 498-503.

[12] M.B. Roe, C.J. Sniffen and L.E. Chase, Techniques for measuring protein fractions in feedstuffs, in: Proc. Cornell Nutrition Conference, Ithaca, NY, 1990, pp. 81-88.

[13] C.J. Sniffen, J.D. O'Connor, P.J. Van Soest, D.G. Fox and J.B. Russell, A net carbohydrate and protein system for evaluating cattle diets: II. Carbohydrate and protein availability, J. Anim. Sci. 70 (1992), 3562-3577.

[14] V.M. Thomas and W.M. Beeson, Feather meal and hair meal as protein sources for steer calves, J. Anim. Sci. 45 (1977), $819-825$.

[15] A.M. Walker, FTIR microspectroscopy as a tool for evaluating the digestibility characteristics of cereal grains fed to ruminants, MSc thesis, University of Saskatchewan, Saskatoon, SK, Canada, 2007.

[16] D.L. Wetzel and S.M. LeVine, Biological applications of infrared microspectroscopy, in: Infrared and Raman Spectroscopy of Biological Materials, Practical Spectroscopy Series, Vol. 24, H.-U. Gremlich and B. Yan, eds, Marcel Dekker, New York, 2001, pp. 101-142.

[17] P. Yu, Application of advanced synchrotron radiation-based Fourier transform infrared (SR-FTIR) microspectroscopy to animal nutrition and feed science: A novel approach, Br. J. Nutr. 92 (2004), 869-885.

[18] P. Yu, Protein secondary structures ( $\alpha$-helix and $\beta$-sheet) at a cellular level and protein fractions in relation to rumen degradation behaviours of protein: A new approach, Br. J. Nutr. 94 (2005), 655-665.

[19] P. Yu, Synchrotron IR microspectroscopy for protein structure analysis: Potential and questions, Spectroscopy 20 (2006), $229-251$.

[20] P. Yu, H. Block, Z. Niu and K. Doiron, Rapid characterization of molecular chemistry, nutrient make-up and microlocation of internal seed tissue, J. Synchrotron Rad. 14 (2007), 382-390.

[21] P. Yu, D.A. Christensen, C.R. Christensen, M.D. Drew, B.G. Rossnagel and J.J. McKinnon, Use of synchrotron FTIR microspectroscopy to identify chemical differences in Barley endosperm tissue in relation to Rumen degradation characteristics, Can. J. Anim. Sci. 84 (2004), 523-527.

[22] P. Yu, J.J. McKinnon, C.R. Christensen and D.A. Christensen, Using synchrotron-based FTIR microspectroscopy to reveal chemical features of feather protein secondary structure: Comparison with other feed protein sources, J. Agric. Food Chem. 52 (2004), 7353-7361.

[23] P. Yu, J.J. McKinnon, H.W. Soita, C.R. Christensen and D.A. Christensen, Use of synchrotron-based FTIR microspectroscopy to determine protein secondary structures of raw and heat-treated brown and golden flaxseeds: A novel approach, Can. J. Anim. Sci. 85 (2005), 437-448. 


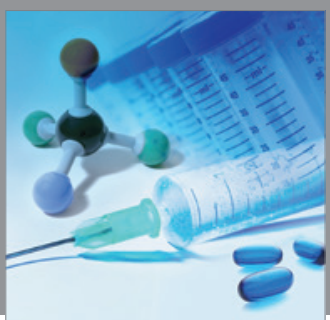

International Journal of

Medicinal Chemistry

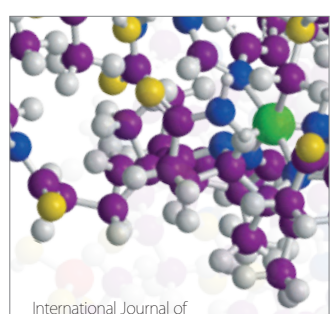

Carbohydrate Chemistry

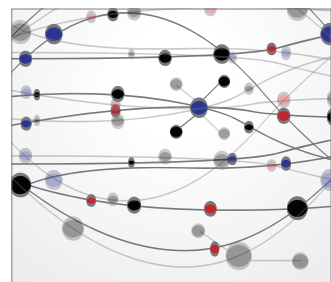

The Scientific World Journal
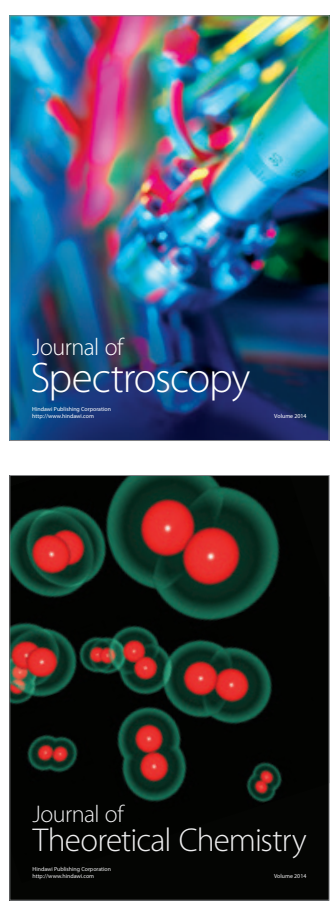
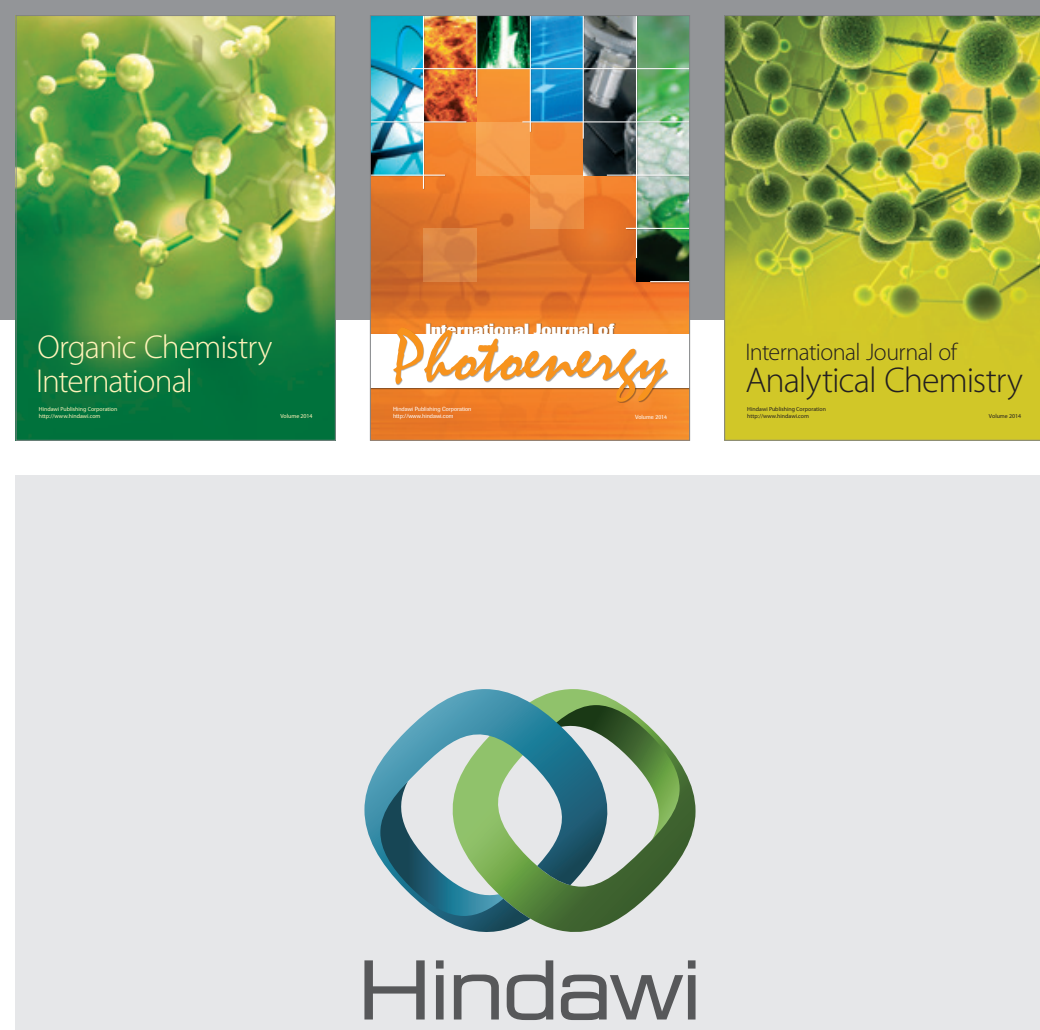

Submit your manuscripts at

http://www.hindawi.com
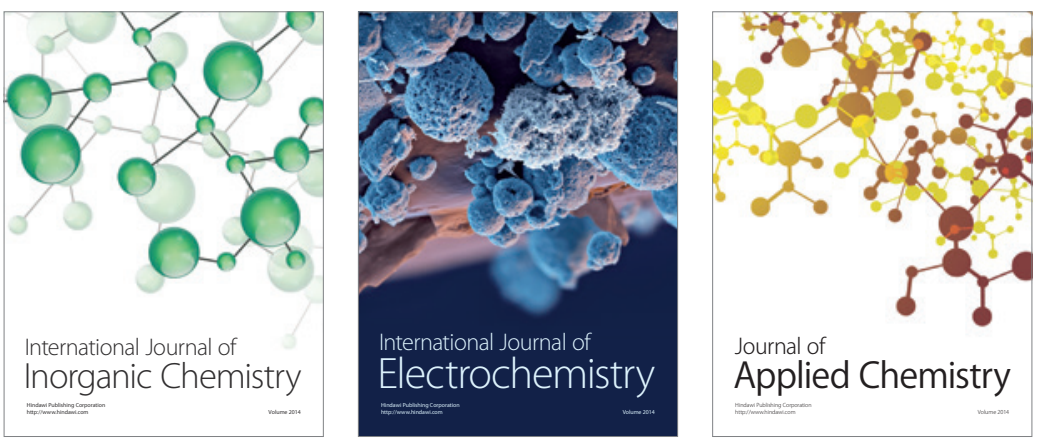

Journal of

Applied Chemistry
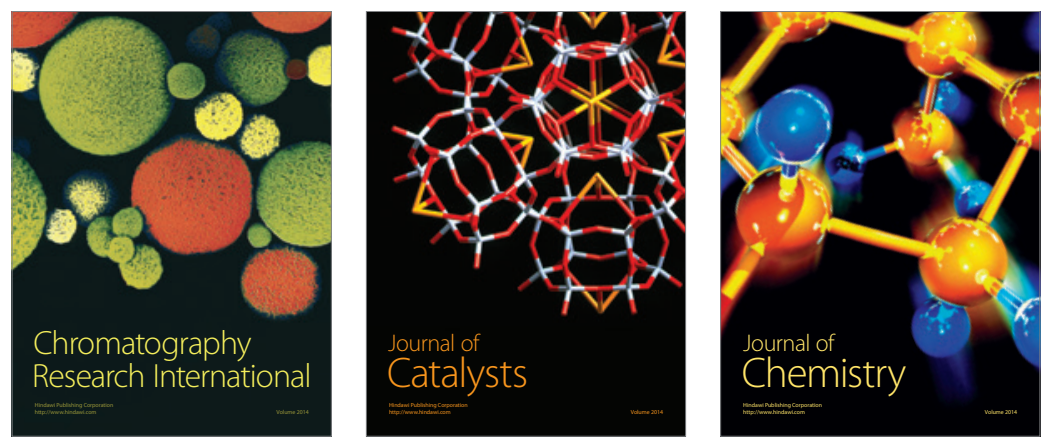
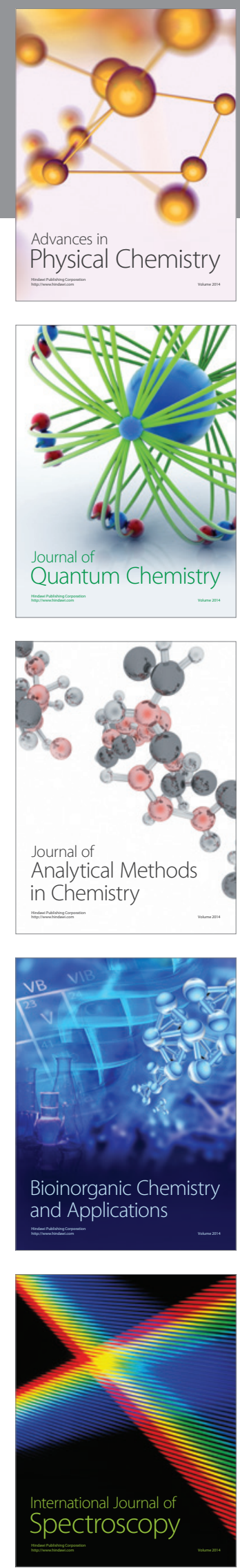